\title{
APHTHOUS ULCERATION - RISK FACTORS AMONG DENTAL STUDENTS AT KHYBER COLLEGE OF DENTISTRY, PESHAWAR
}

\author{
Sanna Safi ${ }^{1}$, Saima Manzoor ${ }^{2}$, Umar Nasir $^{3}$, Fahim Ullah ${ }^{4}$, Noor Durrani ${ }^{5}$, Farooq Taj ${ }^{6}$
}

\section{ABSTRACT: \\ OBJECTIVES:}

The aim of this study was to assess the risk factors of aphthous ulceration (AU) among dental students.

\section{METHODOLOGY:}

This cross-sectional study was conducted at Khyber College of Dentistry, Peshawar in March 2021 among dental students of all four professional years. It was a questionnaire-based study. Questionnaire comprised of demographics and questions about aphthous positivity, risk factors. Risk factors were stress, family history, menstruation (hormonal changes), food allergy, gastrointestinal diseases and medication. Most questions were closed ended. Hospital Anxiety, and Depression Scale (HADS) was used to assess anxiety and depression.

\section{RESULTS:}

Total of 245 dental students responded to questionnaire. Out of 245 dental students, 117 (47.8\%) gave a positive history of $A U$. Mean age in AU positive subjects was $23 \pm 1.5$ years. AU was seen in males (48.7\%) and females (51.3\%) with no association between them. Among risk factors, 69 (28.2\%) had positive family history, 93 (38\%) had stress and $8(3.3 \%)$ reported menstruation. Present study included spice (3.7\%), fast food (0.4\%), sweets $(0.4 \%)$, dry fruit $(0.4 \%)$ and walnut $(0.4 \%)$ as food allergies related to AU. Only 13 (5.3\%) reported a gastrointestinal disease. Medication like NSAIDS and antihypertensive were not involved in any AU case. Anxiety and depression was present in $65 \%$ and $38.5 \%$ with $A U$ positivity.

\section{CONCLUSION:}

Stress was the most common risk factor and positive family history turned out to be the second common risk factor for $A U$ among dental students.

KEYWORDS: Aphthous Ulceration, Risk Factors, Dental Students, HAD Scale

How to cite this article:

Safi S, Manzoor S, Nasir U, Ullah F, Durrani N, Taj F. Aphthous Ulceration - Risk Factors Among Dental Students at

Khyber College of Dentistry Peshawar. J Gandhara Med Dent Sci. 2021;8(3): 47-52

DOI: https://doi.org/10.37762/jgmds.8-3.195 
Correspondence

'Sanna Safi, Lecturer, Department of Oral Medicine, Khyber Medical University Institute of Dental Sciences, Kohat

Cell\# 0331-4304365

Email: sannasafi15@gmail.com

${ }^{2}$ Demonstrator, Department of Oral \& Maxillofacial Surgery, Khyber College of Dentistry, Peshawar

${ }^{3}$ Assistant Professor, Department of Oral Biology,

Khyber Medical University Institute of Dental Sciences, Kohat.

${ }^{4}$ Professor, Department of Prosthodontics, Khyber Medical University Institute of Dental Sciences, Kohat Demonstrator, Department of Orthodontics, Sardar Begum Dental College, Peshawar.

${ }^{6}$ Assistant Professor, Department of Prosthodontics, Khyber Medical University Institute of Dental Sciences, Kohat.

\section{INTRODUCTION:}

Aphthous is derived from a Greek word "aphthall" meaning ulceration. Aphthous ulcer $\mathrm{AU}$ is the most common oral ulcer. It has a prevalence of $25 \%$ out of $4 \%$ of all oral ulcers ${ }^{1}$. Epidemiological data suggests that $A U$ affects $2-66 \%$ of population worldwide ${ }^{2}$. Recurrent and self-limiting nature with involvement of only non-keratinized oral mucosa is the classic clinical presentation of $\mathrm{AU}^{3}$. They appear as small, round ulcers with welldelineated margins and are associated with moderate to intense pain ${ }^{4}$. Aphthous ulcer AU is categorised into 3 types as minor, major and herpetiform on basis of size. Minor AU accounts for greater than $80 \%$ of all 3 types $^{5}$. Major AU can lead to scarring ${ }^{6}$. $A U$, which is often initiated during childhood, involves both genders evenly while some research shows a female predominance ${ }^{7}$. The largest study on AU included 10,000 young individuals from 21 different countries, which showed that $38.7 \%$ males and $49.7 \%$ females get $\mathrm{AU}$ during their lifetime ${ }^{8}$. A multifactorial aetiology is suggested for $A U$, but exact aetiology remains largely unknown ${ }^{7}$. Factors such as diet, hypersensitivity, medications, hormones, smoking, trauma, and psychological stress are considered as risk factors ${ }^{8}$. Genetics is also linked to $\mathrm{AU}$, many DNA polymorphisms (NOD-like receptor 3 , toll-like receptor 4 , interleukin 6 , E-selectin, IL-1 $\beta$ and TNF- $\alpha$ genes), in particular ${ }^{9}$. In addition to this, evidence of Immune dysfunction as a causative factor also exists ${ }^{8}$. Scholars have suggested that dietary control can lead to $\mathrm{AU}$ remission due to its close relation to diet. In previous studies assessing $A U$ relation to diet, some have shown spicy and fried food as risk factor, while some have verified allergic food for $A U^{10}$. AU occurs at a higher frequency at times of stress. In Indian population, stress turned out to be the most common risk factor leading to recurrent $A U^{11}$. A negative correlation of tobacco with $A U$ is concluded by Axell and Henricsson study due to leukoedema that prevents penetration of antigens into epithelium $^{8}$. Less data is available about risk factors of $\mathrm{AU}$ among dental students. Identification of common risk factors for dental students will allow better control of the $\mathrm{AU}$ by avoiding the trigger/risk factor altogether, thus improving quality of life and performance of dental students as $\mathrm{AU}$ can hamper smooth running of daily routine by affecting speech, food intake and mastication. Also, AU is sometimes source of unnecessary worry and stress, which leads to development of more aphthous ulcers. The aim of this study was to assess the risk factors of $A U$ among dental students.

\section{METHODOLOGY:}

This cross-sectional study was conducted at Khyber college of Dentistry, Peshawar in March 2021. Convenience sampling method was used. Sample included students of all four professional years of BDS (Bachelor of Dental Surgery). House officers, postgraduate residents and faculty were excluded from this survey. A formal ethical approval was sought from the concerned institute before conducting the survey. Questionnaire, validated from Ajmal $M$ et al study ${ }^{6}$, was distributed among participants of study. Questionnaire comprised of demographics of age, gender, and professional year. After providing a very brief description of $A U$, a question with a yes or no for AU occurrence was asked in section 1. Further questions regarding presence of risk factors of $A U$ were put forward in section 2, which must be filled only by those with aphthous positivity. Risk factors that might be related to $A U$ were family history, stress (professional, exam, emotional, social etc), 
menstruation (hormonal changes), food allergy, concomitant gastrointestinal GIT illness (Crohn, celiac disease, ulcerative colitis, Helicobacter H. Pylori, peptic ulceration) and medications. History of smoking was also sought in $\mathrm{AU}$ positive subjects only. Closed ended questions were used. Allergic food item, GIT disease and medication, if any, had to be mentioned separately. Last section of questionnaire was HAD scale to assess stress. HAD-A and HAD-D with a score greater than 7 depicted significant anxiety and significant depression. Data was analysed in SPSS version 25.0. Mean and standard deviation was calculated for quantitative variable like age. Frequency and percentages were calculated for qualitative variables like gender, positive history of $\mathrm{AU}$ and risk factors including anxiety and depression. Associations between categorical variables (AU vs. gender, risk factors) were tested using chi-square test. Statistical significance was set at $P<0.05$ for all associations.

\section{RESULTS:}

Total of 245 dental students responded to questionnaire. Among them 109 (44.5\%) were males and $136 \quad(55.5 \%)$ were females. Mean age of the participants was $22.1 \pm 1.8$ years. Minimum age was 18 and maximum 26 years. Out of 245 dental students, $117(47.8 \%)$ gave a positive history of AU. Among risk factors, $69(28.2 \%)$ had positive family history, 93 $(38 \%)$ had stress and $8(3.3 \%)$ reported menstruation (hormonal changes). Different food allergies seen were spice 9 $(3.7 \%)$, dry fruit $1(0.4 \%)$, fast food 1 $(0.4 \%)$, rice $1(0.4 \%)$, walnut $1(0.4 \%)$, sweets $1(0.4 \%)$ and noodle $1(0.4 \%)$. Peptic ulceration was found in $6(2.4 \%)$, $\mathrm{H}$. pylori in $3(1.2 \%)$, irritable bowel syndrome IBS in $4(1.6 \%)$ and ulcerative colitis in $1(0.4 \%)$. Medications reported were non-significant like anxiolytics, flaggy, mobeverine $\mathrm{HCL}$, omeprazole each with a frequency of $1(0.4 \%)$. Figure 1 showing risk factors below.

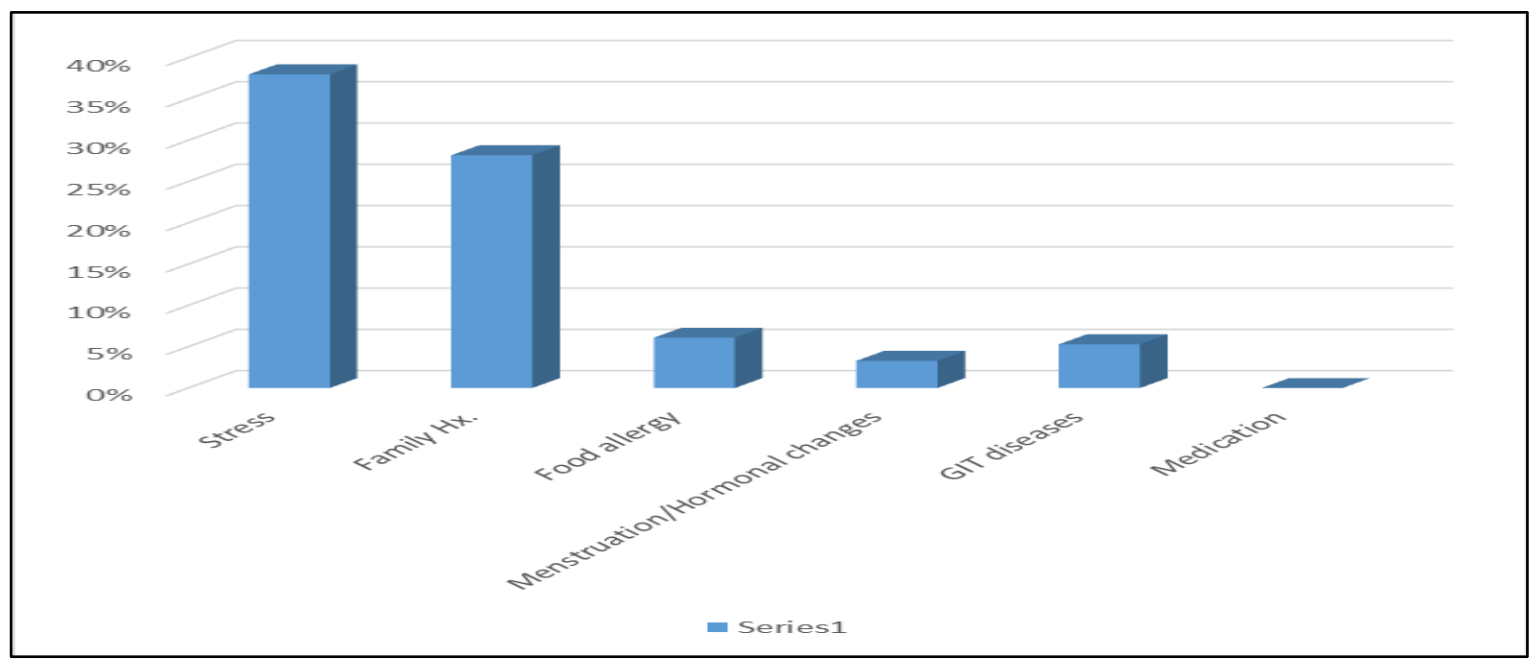

Figure 1: Frequency of Risk Factors of AU in Dental Students

Anxiety was found in $143(58.4 \%)$ dental students whereas depression was seen in 82 subjects $(33.5 \%)$ as depicted by HAD scale. Gender distribution of subjects with $A U$ is shown in Table 1. Mean age in $A U$ positive subjects was $23 \pm 1.5$ years. There were $7(6 \%)$ AU positive students who smoked as well. Frequency of anxiety and depression among dental students with AU positivity is depicted in Table 2 and Table 3.
Table 1: Gender Distribution in AU Positive

\begin{tabular}{|l|l|l|}
\hline Gender & N & $\%$ \\
\hline Male & 57 & 48.7 \\
& & \\
\hline Female & 60 & 51.3 \\
\hline Total & & \\
\hline
\end{tabular}


Table 2: AU Positive Students with Anxiety

\begin{tabular}{|l|l|l|}
\hline Anxiety & N & $\%$ \\
\hline Yes & 76 & 65 \\
\hline No & 41 & 35 \\
\hline Total & 117 & 100 \\
\hline
\end{tabular}

Table 3: AU Positive Students with Depression

\begin{tabular}{|l|l|l|}
\hline Depression & N & $\%$ \\
\hline Yes & 45 & 38.5 \\
\hline No & 72 & 61.5 \\
\hline Total & 117 & 100 \\
\hline
\end{tabular}

No association between $A U$ positivity and gender was found $(p=0.20)$. AU positivity and family history showed a significant relationship $(p=0.00)$. A significant relation of $\mathrm{AU}$ with stress and anxiety was depicted $(p=0.00, p=0.04$, respectively).

\section{DISCUSSION:}

Prevalence of $\mathrm{AU}$ can range between 5$60 \%$, according to the group examined ${ }^{8}$. Among dental students, an increased prevalence of $\mathrm{AU}$ has been reported in several studies ${ }^{7}$. This study showed a frequency of $47.8 \%$, which is quite like $44 \%$ prevalence seen in dental students of Rathod U study ${ }^{1}$. Similarly, Prithi R research study $^{3}$ reported a $50 \%$ incidence among dental students, which is again close to our finding. On the contrary, Al-Johani $\mathrm{K}^{7}$ concluded a low positive history of $21.7 \%$. Dental students are under stress of vast academic syllabus and tough clinical, which can predispose them to greater $A U$ incidence as seen in this study. This study found not much difference of $A U$ occurrence in males (48.7\%) and females $(51.3 \%)$ with no association found between them. In contrast, participants of George S study $^{12}$ reported a higher incidence in females. Sharma $M$ et al findings were same with females affected more than male counterparts $^{13}$. This may be due to lower threshold of females for stress, an important risk factor of $\mathrm{AU}$. Another factor can be presence of hormonal changes due to menstruation and pregnancy. Despite high prevalence seen in females, Leonardo, Ship, Chattopadhyay failed to demonstrate a relation between $A U$ and gender, which is corroborating this study ${ }^{5}$. In an observational study by Complito et al in adult subjects, AU was more common at 38 years of age ${ }^{13}$. In this study too, AU positivity increased with increasing age with a minimum of $0.9 \%$ at 18 years. Mean age with SD for aphthous ulcer AU positivity was $23 \pm 1.5$ years. Usha $R$ et al results, on the other hand, showed 19-20 years as prevalent AU age group ${ }^{1}$. With increasing age, stressors of life also increase. As the age increases, professional year also increases which ultimately results in greater workload, greater fear of failure, and more thoughts for future job. Stress was the most common risk factor $(38 \%)$ in the present study with $65 \%$ anxiety and $38.5 \%$ depression. A significant association of $A U$ was found with stress and anxiety in this study. Al-Johani $\mathrm{K}$ results showed stress as the most frequent risk factor $^{7}(53 \%)$, which is in accordance with this result. About association, a positive correlation of $A U$ with stress was also stated in Sharma M et al study ${ }^{13}$. Ajmal $M$ et al study similarly depicted an association between anxiety and $\mathrm{AU}^{8}$. Stress hormone, cortisol, is at a higher level in saliva of patients with AU. Depression was not related to $A U$ significantly in the current survey $(p=0.11)$, which is very much in accordance with SotoAraya results ${ }^{8}$. Stress and anxiety among dental students can be multifactorial from professional exam stress to Covid-19 related stress and anxiety. Covid-19 related stress could be more in dental students as compared to others as most of the dental procedures involve aerosols, thereby elevating the risk of contracting the disease. Positive family history increases susceptibility to $\mathrm{AU}^{9}$. Present study revealed a positive family history as the second common risk factor $(28.2 \%)$, which depicted a statistically significant relationship. Similarly, a significant association of $\mathrm{AU}$ with a positive family history was found in George S et al study ${ }^{12}$. But Jabar SK et al reported positive family history in $60 \%,{ }^{14}$ which is greater than results of this study. It has been postulated that more severe $\mathrm{AU}$ with an onset at an early age is seen in patients with a positive 
family history ${ }^{15}$. Another study showed $40 \%$ of patients with a family predisposition ${ }^{14}$ whereas in this study, it is $28.2 \%$. Positive family history marks the genetic predisposition of AU. Menstruation was reported in $8(3.3 \%)$ like Maged A findings of $2 \%{ }^{16}$. Ajmal et al found a relation between $\mathrm{AU}$ and menstruation whereas most of the other studies have not established an association between the above two ${ }^{8}$. A small percentage of menstruation as risk factor can be due to its association with females only whereas males do not exhibit any obvious event of monthly hormonal changes. Present study, with low frequency, included spice $(3.7 \%)$, fast food $(0.4 \%)$, sweets $(0.4 \%)$, dry fruit $(0.4 \%)$ and walnut $(0.4 \%)$ as food allergies related to $\mathrm{AU}$. In this study, total $6.1 \%$ students with $\mathrm{AU}$ reported food allergy. In Ajmal et al study, $11.8 \%$ students had food allergy as risk factor $^{8}$. Lakdawala study exhibited association of $A U$ with spicy food ${ }^{5}$. Sweet and acidic intake can cause $A U$ by changing $\mathrm{pH}$ inside oral cavity. Nuts can reduce AU due to the lubrication of oral mucosa by their unsaturated fatty acids ${ }^{10}$. Only $13(5.3 \%)$ students reported a gastrointestinal disease (H. pylori, peptic ulceration, ulcerative colitis, IBS). Similarly, no association was shown between $A U$ and systemic diseases like celiac, Crohn's in Queiroz study ${ }^{17}$. H.pylori was positive in 3 students (1.2\%), which according to Al-Amad study ${ }^{18}$ is not associated with $\mathrm{AU}$. In this study, medication like NSAIDS and antihypertensive, which are commonly notorious for $\mathrm{AU}$, were not mentioned in any AU case. This may indicate that medication is not a common and important risk factor for $\mathrm{AU}$.

Smoking was present in $6 \%$ of participants with aphthous positivity contrary to the fact that smoking is protective against $A U$. This can be attributed to co-existence of other risk factors like stress and family history simultaneously with smoking. This is in accordance with $6 \%$ smoker patients in Maged A et al study but two of them reported decreased frequency of $\mathrm{AU}$ after starting smoking $^{16}$.

\section{CONCLUSION:}

Stress, the most common risk factor for $A U$ among dental students, is significantly related to AU. Educational and public health programmes on $A U$ and stress can help increase this awareness. This could be the way forward for dental students to improve quality of life against $A U$ by either tackling their stress levels themselves or seeking psychological/psychiatric help whenever required.

\section{LIMITATIONS:}

This study did not include post-graduate dental students which if included would have helped in validating the results even further.

CONFLICT OF INTEREST: None

FUNDING SOURCES: None

\section{REFERENCES:}

1. Rathod U, Kulkarni S, Agrawal V. Prevalence of recurrent apthous ulcers in dental student: a questionnaire-based study. Int $\mathrm{J}$ Health Sci Res. 2017;7(12):80-3.

2. Hamedi $S$, Sadeghpour $O$, Shamsardekani MR, Amin G, Hajighasemali D, Feyzabadi Z. The most common herbs to cure the most common oral disease: stomatitis recurrent aphthous ulcer (RAU). Iran Red Crescent Med J. 2016;18(2):e21694.

3. Prithi $R$, Dharman $S$. Study on prevalence of recurrent aphthous ulcer among college students. Res $\mathrm{J}$ Biol Pharm Chem Sci. 2016;7(6):1391-8.

4. Aslam A, Hassan SH, Khan DA, Chaudhary MA. Psychological stress associated with aphthous ulcers and temporomandibular disorders. Pak Armed Forces Med J. 2017;67(3):453-7.

5. Lakdawala YA, Masood S, Gulzar I, Batool F, Arshad R. Frequency of aphthous ulcers - a study. Pak Oral Dent J. 2017;37(3):419-21.

6. Minhas S, Sajjad A, Kashif M, Taj F, Waddani HA, Khurshid Z. Oral ulcers presentation in systemic diseases: an update. Open Access Maced J Med Sci. 2019;7(19):3341-7.

7. Al-Johani K. Prevalence of recurrent aphthous stomatitis among dental students: a cross sectional study. J 
Contemp Dent Pract. 2019;20(8):893-5.

8. Ajmal M, Ibrahim L, Mohammed N, Al-Qarni H. Prevalence and psychological stress in recurrent aphthous stomatitis among female dental students in Saudi Arabia. Clujul Med. 2018;91(2):216-21.

9. Rivera C. Essentials of recurrent aphthous stomatitis. Biomed Rep. 2019;11:47-50.

10. Du Q, Ni S, Fu Y, Liu S. Analysis of dietary related factors of recurrent aphthous stomatitis among college students. Evidence Based Complementary Altern Med. 2018:2907812:1-7.

11. Khare P, Sharva V, Handa H, Amit K, Jain $M$. Association of recurrent aphthous stomatitis and psychological stress in school going teenagers of Bhopal city, central India: a descriptive study. Indian J Multidiscip Dent. 2017;7:82-6.

12. George S, Joseph BB. A study on aphthous ulcer and its association with stress among medical students of an Indian medical institution. Int J Contemp Med Res. 2016;3(6):1692-5.

13. Sharma M, Gupta R, Singh S. Correlation of psychological stress with recurrent aphthous stomatitis among dental students in an educational institution. Int $\mathrm{J}$ Appl Dent Sci. 2017;3(4):455-8.

14. Jabar SK, Ahmed SM, Issa NJ, AlKhasssaki Al. The risk factors of recurrent aphthous ulceration among patients in misan governorate. Indian J Forensic Med Toxicol. 2020;14(3):1588-92.

15. Toppo NA, Lazarus A, Seth RJ, Bhargava OP, Yadav KS, Kasar PK. Introduction of integrated teaching learning module in second M.B.B.S. curriculum. Int J Contemp Med Res. 2016;3:1275-9.

16. Maged A, Abdel MW. Prevalence of aphthous and aphthous like ulcers and their relation to precipitating factors among a sample of Egyptian population. Egypt Dent J. 2017;63(3):2377-88.

17. Queiroz SI, Silva MV, Medeiros AM, Oliveira PT, Gurgel BC, Silveira ÉJ. Recurrent aphthous ulceration: an epidemiological study of etiological factors, treatment and differential diagnosis. Ann Bras Dermatol. 2018;93(3):341-6.

18. Al-Amad $\mathrm{SH}$. Helicobacter pylori and gastric hyperacidity, and their association with recurrent aphthous stomatitis. Int $\mathrm{J}$ Oral Maxillofac Surg. 2020;49(12):1599-1604.

\section{CONTRIBUTORS}

1. Sanna Safi - Concept \& Design; Data Analysis/Interpretation; Drafting Manuscript; Critical Revision; Supervision; Final Approval

2. Saima Manzoor - Data Acquisition; Critical Revision

3. Umar Nasir - Drafting Manuscript; Supervision

4. Fahim Ullah - Drafting Manuscript; Supervision

5. Noor Durrani - Critical Revision; Final Approval

6. Farooq Taj - Drafting Manuscript; Critical Revision; Final Approval

LICENSE: JGMDS publishes its articles under a Creative Commons Attribution Non-Commercial Share-Alike license (CC-BY-NC-SA 4.0). COPYRIGHTS: Authors retain the rights without any restrictions to freely download, print, share and disseminate the article for any lawful purpose. It includes scholarly networks such as Research Gate, Google Scholar, LinkedIn, Academia.edu, Twitter, and other academic or professional networking sites. 